Вестник ПСТГУ

IV: Педагогика. Психология

2016. Bon. 1 (40). C. 121-128
Коган Ирина Михайловна,

канд. психол. наук

Медииинский информаиионно-консультативный иентр (Мюнхен)

irina kogan@web.de

\title{
Слово
}

\author{
И. М. КОГАН
}

В статье описано влияние различных слов на человека. На примере литературных образов произведений Ф. М. Достоевского «Бесы» и «Братья Карамазовы» показано целительное и разрушительное действие слова и анти-слова. Обозначен основной критерий различения слов, в основе которого лежит мотивация: то, ради чего они сказаны. В основе разрушительного действия анти-слова лежит мотив самоутверждения. Показаны последствия внедрения таких слов в сознание. И наоборот, в основе целительного слова благо другого: поддержка совести как основной духовной силы, способной исцелить человека от его душевных недугов. Раскрыта психологическая сущность суесловия и его негативное влияние на личность.

Описаны разные типы слов в трактовке М. М. Бахтина (слова с лазейкой, имеющие скрытую установку на то, чтобы быть признанными другими, слова, в которых нет живого, личного тона, акцента, нарочитые, сдержанно-презрительные, а также проникновенные слова, благотворно действующие на человека, способные его исцелять и укреплять).

Сила воздействия слова на человека хорошо известна всем из собственного опыта. Слово может задать импульс, привести в движение, исцелить, поддержать, вселить надежду, восстановить и вдохновить, а может, наоборот, придавить, сломать, убить. Отчего слово обладает такой мощью, такой силой воздействия?

Слово носитель смысла, в нем выражается интенция мысли, чувства, их энергия. Слово - это оформленная энергия, обладающая силой воздействия. Слово, подобно человеку, - материальный носитель духовного, энергия которого может быть либо созидающая, либо разрушающая: энергия зла (дух зла) оформляется в злом слове, энергия добра (дух любви) - в добром слове. Действие разных слов, на двух полюсах разное: на одном полюсе - слово жизнеутверждающее, светлое, сильное, чистое, на другом - разрушительное, смертоносное.

Есть слова, лишенные смысла, - пустые, используемые всуе (суете). Суесловие лишено всякого смысла и потому не благотворно. Не без участия пестрого потока информации слово перестало восприниматься серьезно, в результате в обществе укоренилась привычка не придавать значения словам. Происходит потеря ценности слова. Суть его девальвации видится в отчуждении смысла от слова. Раздвоение внутри самого слова, выхолащивание смысла превращает слово в оболочку, в фантик без конфеты. Лишенное смысла слово, завладев вниманием человека, лишает его времени, сил, смысла и, как воронка, затягивает челове- 
ка, что неявным образом может ослаблять духовный, интегрирующий потенциал человека. Выхолощенное, суетное, безжизненное, ненужное, не к месту и не ко времени сказанное слово неявным, косвенным образом становится анти-словом, тем словом, которое поддерживает негативные, теневые стороны человека.

Дар слова - это дар духовного общения, которое по-разному влияет на внутренний мир человека - его убеждения, установки, чувства, мировоззрение, определяющие действия, поступки и жизнь. Внутренний мир человека имеет еще и особую глубину: это «сокровенный сердца человек в нетленной красоте кроткого и молчаливого духа» (см. 1 Петр 3. 4), потребности которого - мир, радость, любовь, сострадание, свет, чистота. Зло состоит в порабощении внутреннего человека внешним, в забвении его интересов и потребностей. Часто внутренний человек не осознается. Он может быть вытеснен, не развит. «В патологических условиях... место внутреннего человека занимает чужая и чуждая личность, факт, известный под названием одержимости» ${ }^{1}$ Когда же внутренний человек руководит жизнью человека (действиями, мыслями, чувствами), тогда слово становится действием, а человек -цельной, зрелой личностью.

Внутренний человек описывается как образ Божий, духовное Я, дух, ум, энергетика которого облечена в слово или внутренний Логос, как семя, заложенное в человека. «Логос (греч. logos) - термин древнегреческой философии, означающий одновременно “слово” ... когда говорят о Логосе, имеют в виду наиболее глубинную, устойчивую и существенную структуру бытия, наиболее существенные закономерности развития мира»².

Христианин сочетает в себе действие «трансцендентного Логоса и имманентного, врожденного Логоса» ${ }^{3}$. Пробраться к своему Логосу трудно из-за препятствий, стоящих на пути к нему. Внутренний Логос соответствует Логосу абсолютной истины. Препятствием становится все то, что этой истине не соответствует, противоречит. Например, искаженное мировоззрение, эгоистичные желания и установки, действия и чувства, использование дара слова напрасно (всуе), в отрыве от его предназначения (суесловие), мертвые и гнилые слова, раздражающие, отравляющие своим ядом жизнь человека, толкающие на преступление. Без признания факта этих препятствий и покаяния как отказа от «своего», без обращения к Логосу трансцендентному, пробиться к своему внутреннему Логосу, этой «частице Божества», невозможно. Но «кто сумел... дойти до Логоса в сердие, тот открывает в себе неисчерпаемый источник силы и жизни...» ${ }^{4}$

М. М. Бахтин, на примере творчества Достоевского, выделяет разные типы слов, в зависимости от личности говорящего, по-разному влияющие на слушателей. Например, это слова с лазейкой, имеющие скрытую установку на то, чтобы быть признанными другими (исповедь Ипполита в романе «Идиот», который хотел застрелиться, чтобы Аглая прочла его исповедь, его слово - не завершенное, не знающее точки опоры). Также это слово, в котором нет живого, личного

\footnotetext{
${ }^{1}$ Позов А. Основы древне-церковной антропологии. Мадрид, 1965. С. 236.

${ }^{2}$ Словарь по логике. М., 1997. (URL: http://filosof.historic.ru/books/item/f00/s00/z0000973/ index.shtml).

${ }^{3}$ Позов А. Указ. соч. С. 251

${ }^{4}$ Там же. С. 253.
} 
тона, акцента, нарочитое и сдержанно-презрительное (Ставрогин, Версилов): «говорить, отвернувшись от слушателя» 5 .

Однако есть слова, способные благотворно действовать на человека, исцелять и укреплять его. М. М. Бахтин, изучая творчество Достоевского как автора, для которого характерно серьезное отношение к другому самосознанию как к свободному и самостоятельному, как автора, позволяющего героям жить и действовать по логике своего развития, делает следующее открытие: он выявляет так называемое проникновенное слово. «Мышкин - уже носитель проникновенного слова, т. е. такого слова, которое способно активно и уверенно вмешиваться во внутренний диалог другого человека, помогая ему создавать свой собственный голос. Но это проникновенное слово, призыв к одному из голосов другого как истинному, - по замыслу Достоевского - у Мышкина никогда не бывает решающим. Оно лишено какой-то последней уверенности и властности $<\ldots>$ им руководит скорее боязнь своего собственного слова (в отношении к другому), чем боязнь чужого слова. Он боится своих подозрений и предположений» ${ }^{6}$.

Каким же должно быть проникновенное слово по замыслу Достоевского? «По замыслу, оно должно быть < ..> , не расколотым словом, словом без оглядки, без лазейки, без внутренней полемики» ${ }^{7}$

Носителями таких слов у Достоевского являются Алеша Карамазов, старец Зосима. Ниже будет приведен пример слова Алеши, обращенного к брату Ивану. Это проникновенное слово - тихое, проникнутое глубоким пониманием внутренней борьбы личности в ее поисках и терзаниях, не давящее, не напористое, но оно твердое, уверенное, лишенное нерешительности и расколотости.

Дар слова призван возродить жизнь внутреннего человека - все его добрые намерения, чувства, установки, действия. Живое человеческое слово - это слово, которое соответствует внутреннему Логосу или хотя бы приближается к полноте соответствия ему. Если слово не содержит обращенности к Логосу, тогда - это мертвое, отравленное слово. Или оно пустое, в нем либо просто отсутствует энергия любви, либо даже присутствует негативная, разрушительная сила. Живое человеческое слово способно восстановить и возродить в человеке созидательную силу любви, поддержать его дух. Слова иного рода разрушительным образом действуют на человека. Таких слов очень много в современном мире и информационном пространстве. В информационной войне слово, образ - это оружие, фактор негативного разрушительного воздействия на душу человека.

В качестве примера действия такого отрицательного слова (анти-слова) на человека, можно назвать других героев Ф. М. Достоевского: Ивана Карамазова и Смердякова.

Разговор, произошедший между этими героями, поражсает способом сообщения, за которым кроется преступление. Основой разговора послужило духовное родство лакея Смердякова с Иваном Карамазовым, проявившееся в некой фамильярности общения. Смердяков - подлое (и вместе с этим страдающее) существо, Иван бунтует против Бога, конкретно же их объединяет ненависть к отиу Ивана - Федору

\footnotetext{
${ }_{5}^{5}$ Бахтин М. М. Проблемы творчества Достоевского. Л., 1929. С. 205.

${ }^{6}$ Там же. С. $198-199$.

${ }^{7}$ Там же. С. 210.
} 
Карамазову, которую Смердяков учуял в Иване. Лакею нужен идейный покровитель злого намерения, сочувствующий и тем соучаствующий, так как полностью принять на себя ответственность за убийство Федора Карамазова Смердяков не может. Разговор между Иваном и Смердяковым, состоявшийся незадолго до убийства, полон намеков и недоговоренностей, в нем отсутствуют слова, которые могли бы прямо указывать на замыслы персонажеей, однако последствия этого разговора свидетельствуют о контексте, который содержит в себе разрушительную интенцию их взаимодействия. Смердяков, замыслив убийство отиа Карамазова, нуждается в «покровительстве» Ивана, Ивану же трудно на это согласиться: в нем идет внутренняя борьба. Понимая это, Смердяков дает Ивану фору - он намеками предлагает ему уехать в то время, когда будет совершено преступление, дабы отвести от Ивана подозрения, дать ему алиби, подстраховать. Иван, конечно, понимает подлость ходов Смердякова и все же соблазняется этим предложением. Он уезжает (хотя не собирался), чем отводит от себя подозрение и молчаливо соглашается на преступление. Они взаимно, но косвенно, не открыто, поддерживают намерения друг друга. Иван своим согласием подталкивает Смердякова на преступление. «Я уеду, а у вас вот что произойдет» ${ }^{8}$. Разрушительное действие слов проявляется в последующем состоянии людей, их произнесших и их воспринявщих. Иван уезжает, но «на душу его сошел вдруг такой мрак, а в сердце заныла такая скорбь, какой никогда он не ошущал прежде во всю жизнь... - Я подлещ! - прошептал он про себя»9. Что следует из этого разговора, все знают: преступление - смерть двух человеки мучительная внутренняя борьба Ивана.

Ярким примером разрушительного действия анти-слова являются другие герои романа Достоевского «Бесы». Несомненная актуальность данной темы не позволяет нам оставить без внимания это, к сожалению, пророческое произведение. В романе все взаимосвязано и все влияют на всех - в негативном смысле. Как действует анти-слово и каковы последствия этого действия, видно из поступков героев романа Кириллова, Петра Верховенского, Верховенского старшего, Ставрогина.

Кириллов замыслил самоубийство, но не решается совершить его, колеблется, что-то останавливает его. Находится человек, который пытается всячески поддержсать страшные намерения Кириллова, - Петр Верховенский (П. В.). Последнему это выгодно, ибо на самоубийиу, который обещает в предсмертной записке навесить на себя чужие преступления, можно будет легко свалить собственные преступления. Сначала П.В. поддерживает намерения Кириллова, а затем подталкивает его к их исполнению: уже не ласково и с намеками, а нагло и напористо доводит Кириллова до осушествления некогда зародившегося намерения.

Кириллов страдает почти тем же: он борется с Богом за власть принимать даже самые крайние решения - лишать себя жизни. Идея, «съевшая» Кириллова, - это идея своеволия, на чем и «играет» П. В.:

«-Вы сами соединили ваш план с нашими действиями. Рассчитывая на ваш план, мы уже кое-что предприняли, так что вы уж никак не могли бы отказаться, потому что нас подвели.

\footnotetext{
${ }^{8}$ Достоевский Ф. М. Братья Карамазовы. М., 1991. Т. 1. С. 351.

${ }^{9}$ Там же. С. 359.
} 
- Права никого (Кириллов. - И.К.).

- Понимаю, понимаю, ваша полная воля, а мы ничто, но только чтоб эта полная ваша воля совершилась» ${ }^{10}$.

Занимаясь самоанализом, вернее самооправданием, Петр Верховенский демонстрирует роль «идеала» (анти-идеала) в укреплении своих преступных замыслов. Для него таким идеалом явился Ставрогин: «Нет на земле иного, как вы!' Я вас с заграницы выдумал; выдумал, на вас же глядя. Если бы не глядел на вас из угла, не пришло бы мне ничего в голову.» ${ }^{11}$.

Не лишено интереса то, как Достоевский раскрывает действие анти-слова в воспитании. Петр Верховенский и Ставрогин - оба детища Верховенского старшего. П.В. - брошенный им его сын, вспоминая папу, рассказывает: «В Петербурге, когда я был еще гимназистом, не он ли будил меня по два раза за ночь, обнимал и плакал, как баба, и как вы думаете, что рассказывал мне по ночам-то? Вот те же скоромные анекдоты про мою мать! От него первого услыхал» ${ }^{12}$.

Ставрогин - воспитанник Верховенского старшего, которому доверила воспитание своего сына Варвара Петровна Ставрогина, почитая того за просвещенного и благородного человека, однако «педагог несколько расстроил нервы своего воспитанника» ${ }^{13}$. Достоевский сообщает некоторые подробности такого воспитания: «Надо отдать справедливость Степану Трофимовичу, он умел привязать к себе своего воспитанника. Весь секрет его заключался в том, что он и сам был ребенок. ... Он не задумался сделать своим другом такое маленькое существо, едва оно капельку подросло... что между ними не оказалось ни малейшего расстояния. Он не раз пробуждал своего десяти- или одиннадцатилетнего друга ночью, единственно чтоб излить пред ним в слезах свои оскорбленные чувства или открыть ему какой-нибудь домашний секрет, не замечая, что это совсем уже непозволительно» ${ }^{14}$.

Отсутствие дистанции, ночные пробуждения детей с целью излить в их неокрепшие души свои страсти сделали свое дело: выросшие дети стали носителями зла и преступлений. Зло это неприметным образом было влито в их души еще в детстве.

Двойственная природа человека, в которой поддерживаются теневые стороны, тем более со стороны авторитетного лица - взрослого (отца и воспитателя), и при этом не взращивается добро, в результате искажает душу, и зло разрастается. Поддержка анти-слова в детстве очень опасна.

Чем же «болел» взрослый в лице Степана Трофимовича Верховенского, который способен был отравить души двоих детей: сына и воспитанника, что положило начало стольким преступлениям? В его предсмертной исповеди он обозначил суть своих заблуждений: «...я всю жизнь мою лгал. Даже когда говорил правду. Я никогда не говорил для истины, а только для себя <...> Главное в том, что я сам себе верю, когда лгу. Всего труднее в жизни жить и не лгать...и ... и соб-

\footnotetext{
${ }^{10}$ Достоевский Ф. М. Бесы. // Собрание сочинений: В 10 т. Т. 7. М., 1957. С. 580

${ }^{11}$ Там же. С. 442.

${ }^{12}$ Там же. С. 323.

${ }^{13}$ Там же. С. 43.

${ }^{14}$ Там же.
} 
ственной лжи не верить, да, да, вот это именно!...» ${ }^{15}$ (курсив мой. - И. К.) Что это за слово, которое для себя, а не для истины?

Достоевский гениально подметил самую существенную характеристику анти-слова. Главное свойство его, позволяющее отличить слово истинное от слова ложного (а ложные слова часто облекаются в оболочку правды и истины), это то, ради чего они сказаны. В ложном слове заложен мотив самоутверждения - «ради себя». Это один из основных критериев различения слов. Самоутверждаясь, человек часто убежден в справедливости своих слов и намерений. В замкнутом на себе, эгоцентричном самосознании мотив самоутверждения не осознается, он скрыт как для самого говорящего, так и для воспринимающего это слово, так как направлен на себя, свои представления, свое понимание, потому за своей субъективной «правдой» не видит правды объективной.

У человека, который направлен не на себя и свое, а устремлен к правде и подлинности, нет нужды в самоутверждении, мотив самоутверждения «ради себя» такому человеку не свойственен.

Другое воздействие имеют на душу слова иелительные. Такое слово произносит Алеша Карамазов, чтобы спасти брата Ивана. Иван находится в мучительной борьбе с собой, со своей совестью. Он разговаривает с тем, что он по собственной воле взрастил в себе: с темными сторонами своей души, которые персонализировались в образ черта. Алеша духовно провидел это, и он, «посланный Богом», приходит $\kappa$ брату, чтобы поддержать вытесненный голос совести Ивана, с которым тот борется, а значит борется с собой. Как делает это Алеша? Деликатно, с любовью, верой и надеждой на его возрождение. На вопрос Ивана: «Кто же убийца?» Алеша сначала тихо и проникновенно отвечает: «Ты сам знаешь кто». Иван как будто не понимает, и Алеша снова, но уже бессильно повторяет: «Ты сам знаешь кто». Иван враждует с совестью, потому не понимает и продолжает вопрошать Алешу: «Да кто?» На что Алеша отвечает почти шепотом: «Убил отиа не ты». Так называется сама глава: «Не ты, не ты.»"${ }^{16}$.

Алеша озвучивает голос «глубокой совести» Ивана в надежде на то, что это впоследствии поможет ему стать на сторону совести, хотя он пока враждует с ней, потому и Алешу отвергает. И впоследствии поступок Алеши действительно помогает Ивану: он пытается поступить по совести, идет в суд и свидетельствует о своем преступлении, но делает это как бы вынужденно, ему это мучительно трудно, он не до конца готов утвердиться в вере, потому нет полного покаяния, он бунтует. Но голос совести, некогда поддержанный Алешей, заставляет Ивана признаться публично, что спасает его от полного сумасшествия, становится началом его исцеления, но не снимает - пока - его двойственности.

«Говорить есть не иное что, как возбуждать в слушателе его собственное внутреннее слово» (В. Ф. Одоевский). Логосфера русской культуры, основанная на принципах «диалогического единства мира», «соборности сознания», целостности, имеет славную историю и богатые гармонизирующие возможности для создания коммуникации будущего ${ }^{17}$.

\footnotetext{
${ }^{15}$ Достоевский Ф. М. Бесы. С. 678.

${ }^{16}$ Достоевский Ф. М. Братья Карамазовы. С. 318, 322.

${ }^{17}$ Кемеров В. Философская энциклопедия (URL: http://www.psyoffice.ru/slovar-s284.htm).
} 
Задача диалога - через обращение к внутреннему Логосу помочь возродить внутреннего человека. Способность видеть в другом человеке небесное может укрепить в нем доброе начало. Поэтому задача состоит в том, чтобы содержание наших мыслей, образов, представлений, устремлений, оформленных или не оформленных в слова, составляющих духовное пространство, в котором мы находимся как рыбы в воде, сделать чистым. В мутной воде, как известно, ничего хорошего не водится. Человек своим выбором мыслей, слов, устремлениями может преобразить, очистить духовное пространство, в котором он находится. Если проделать такой мысленный эксперимент: предложить окружающим нас людям вспомнить самый светлый момент их жизни (скорее всего этот момент из детства) и хотя бы немного побыть в атмосфере этих воспоминаний, как изменилась бы атмосфера, в которой находились эти люди! А если одновременно провести такой эксперимент в районе, городе, стране, планете? Как изменилось бы содержание духовной атмосферы земли, даже если это были бы лишь минуты, когда люди погрузились в самые светлые воспоминания!

Период атеизма не прошел бесследно: колокола разбили, гордыню самости утвердили, слово исказили, поэтому пробиваться к живому слову - Логосу очень трудно. Надо преодолевать внутренние препятствия. Но колокол взывает, посылает частоты духа истины, находит отклик в душе. Утвердить его, не дать ему заглохнуть в ложном шуме бессмысленной суеты, злобы, раздражения, «праведного» гнева, слов самости, заглушающих слова жизни, не дающих им проникнуть в сердце и волю человека.

Диалог - это воззвание к жизни слов в душе человека, способных возродить его к добру и свету и восстановить связь двух или множества логосов в одном абсолютном Логосе. Это возможность усилить заглушенные, подавленные глаголы жизни вечной и соединиться в общем хоре светлых и радостных голосов, возгласив: «Слава в вышних Богу...».

Ключевые слова: Слово, анти-слово, суесловие, проникновенное слово, внутренний человек, Ф. М. Достоевский, М. М. Бахтин.

\section{THE WORD}

\section{KogAN}

In the article the action of different words on an person is described. Using the example of characters from Dostoevsky's "Demons" and "The Brothers Karamazov" the curative and destructive action of a word and an anti-word are shown. The main criterion for differentiating words is outlined which is based on the motivation: the reason they are said for. The destructive action of anti-words is based on the motive of self-assertion. The consequences of such words being impressed are shown. Conversely, the curative word is based on the welfare of others: the support of conscience as the main 
spiritual strength being able to heal a person from its mental illnesses. The psychological essence of idle talk and its negative impact on the personality are exposed.

Different types of words as treated by M. Bakhtin are described (words with a loophole, having a hidden attitude towards being recognized by others; words which don't have a vivid, personal mood, including a special profound word able to cure and strengthen a person).

Keywords: word, anti-word, idle talk, profound word, inner person, F. Dostoevsky, M. Bakhtin.

\section{Список литературы}

1. Бахтин М. М. Проблемы творчества Достоевского. Л., 1929.

2. Достоевский Ф. М. Бесы. // Собрание сочинений: В 10 т. Т. 7. М., 1957.

3. Достоевский Ф. М. Братья Карамазовы. М., 1991.

4. Кемеров В. Философская энциклопедия (URL: http://www.psyoffice.ru/slovar-s284. htm).

5. Колпакова М. Ю. Введение в диалогическую психологию, М.: Канон, 2013.

6. Позов А. Основы древне-церковной антропологии. Мадрид, 1965.

7. Словарь по логике. M., 1997 (URL: http://filosof.historic.ru/books/item/f00/s00/z0000973/ index.shtml). 